\title{
Elimination characteristics of sulfonated cobalt phthalocyanine catalyst (Europhtal) from wastewater in natural gas refineries by adsorption using modified natural zeolite
}

\author{
Ali Gharibi ${ }^{1^{*}}$, Benyamin Akhlaghi ${ }^{2^{*}}$, Mohsen Abbasi ${ }^{2^{+*}}$ \\ ${ }^{1}$ Department of process engineering, Third refinery, South Pars Gas Complex, Assaluyeh, Iran \\ ${ }^{2}$ Department of Chemical Engineering, Faculty of Petroleum, Gas, and Petrochemical Engineering (FPCPE), Persian Gulf University, Bushehr, 75169, Iran \\ "These authors contributed equally to this work.
}

\begin{abstract}
The present research introduces adsorption of sulfonated cobalt phthalocyanine catalyst (Europhtal) from the real wastewater that is produced in the mercaptan removal unit (Merox) of the third refinery, South Pars Gas Complex (SPGC), Assaluyeh, Iran. Therefore, novel low-cost natural zeolite modified with polyaluminium chloride (PAC) was investigated as an adsorbent for the treatment of Europhtal wastewater. Central composite design (CCD), as a set of response surface methodology (RSM), was applied to acquire optimum operational conditions such as contact time, $\mathrm{pH}$, adsorbent dosage, and Europhtal concentration. Results showed that the removal percentage of Europhtal in the real wastewater was $93.4 \%$ at best operating condition consisting of a $\mathrm{pH}$ of 6.7 , sonication time of $8 \mathrm{~min}, 0.035 \mathrm{~g}$ of adsorbent. The obtained results were evaluated by adsorption isotherms and kinetic parameters. It was found that the equilibrium data matched the Freundlich model acceptably, with the maximum experimental adsorption capacity of this model was $687.51 \mathrm{mg} \mathrm{g}^{-1}$ at $301.15 \mathrm{~K}$. From the kinetic data, it was revealed that the adsorption process followed the pseudo-second-order kinetic model. Furthermore, the obtained thermodynamic parameters such as $\Delta \mathrm{H}^{\circ}, \Delta \mathrm{S}^{\circ}$, and $\Delta \mathrm{G}^{\circ}$ imply the endothermic essence of adsorption proceeding spontaneously.
\end{abstract}

Keywords: Adsorption, Europhtal, Merox process wastewater, Natural Zeolite, Wastewater Treatment

\section{Introduction}

Nowadays, due to the rapid development of industrial factories, a huge amount of effluents comprised of synthetic dyes are produced. The various significant industries extensively utilize dyes in different activities such as coloring, paper, leather, textiles, cosmetics, and food [1-3]. The molecular decomposition of dyes is affected by the complex structures of dyes [4]. The complex molecular structures of dyes attributed to the existence of aromatic compounds enhance dyes resistance to heat, oxidizing agent, and biodegradation [1]. According to the chemical composition of dyes, they are categorized into acid dyes, azo dyes, basic dyes, disperse dyes, sulfur dyes, pigment dyes, etc. [4]. Among these kinds of dyes, azo dyes, including diazotized amine, which are coupled with an amine or phenol and one or more groups of azo $(-\mathrm{N}=\mathrm{N}-)$, are more versatile and comprise $50 \%$ of the whole dye manufacture

This is an Open Access article distributed under the terms of the Creative Commons Attribution Non-Commercial License (http://creativecommons.org/licenses/by-nc/3.0/) which permits unrestricted non-commercial use, distribution, and reproduction in any medium, provided the original work is properly cited.

Copyright (C) 2022 Korean Society of Environmental Engineers in each year $[4,5]$. It cannot be precisely determined how much dye effluents are empty out by industries to the environment. However, it can be asserted that the amount of dye-containing effluents is quite huge to endanger the lives of humans, flora and fauna [3]. Discharged synthetic dyes and heavy metals from industrial plants affect aquatic life, earth, animal, and human health by entering the natural ecosystem and food chain. They may cause severe environmental pollution [3-7]. The resistance and toxicity characteristics of dyes and heavy metals are harmful to some organisms, including aquatic and none aquatic, and enzymes and inhibit their catalytic activity as well [1, 7]. Moreover, dyes could cause inhalation injuries that will be harmful to the nervous system, liver, and thyroid gland [7]. Besides, physical contact with color might cause skin eruptions [7]. It should be noted that the dyes pollution cause the reduction in light penetration, which has destructive effects on photosynthesis in aquatic environments [7-9].

Received September 10, 2020 Accepted February 03, 2021

${ }^{\dagger}$ Corresponding author

E-mail: m.abbasi@pgu.ac.ir

Tel: +989173239077 Fax: +987733441495

ORCID: 0000-0001-7488-8661 
A vast array of researches in literature have been published concerning discharged dyes and heavy metals to the environment and removing them in effluents, all of which are categorized in the following methods: biodegradation, electrochemical method, chemical method, physio-chemical method. Several procedures, including ion exchange, chemical coagulation, oxidation, adsorption, flocculation, filtration, precipitation, microbiological decomposition, and chromatography, are performed to treat wastewater and enhance the quality of treated-water [1, 7-20].

Adsorption procedure has been perceived as a superior technique for variant separation and purification purposes. This process is widely applied in order to treat continuously aqueous wastes produced by industrial processes. This procedure has been perceived to be highly capable and effective for the removal of dyes in terms of low operational cost, the simpleness and convenience of design, operation easiness, high efficiency, insensitivity to toxic substances, and the reusability of adsorbents [2, 11,21]. Adsorbents are abundant and mostly inexpensive such as alumina, zirconium, diatomaceous earth, activated carbon, cellulose, and the different types of silicates. Although silicates have a large number of applications due to their low cost and suitable physical and chemical strength, most of the adsorbents have disadvantages such as reduced ability in mechanical and thermal resistance and rather a small adsorption capacity for dyes $[1,18,19]$. Among these materials, natural zeolites are the most capable material for heavy metals removal from water and wastewater with adsorption methods. Zeolite is a hydrated aluminosilicate with remarkable sorption ability [16, 22]. Zeolite, as a suitable adsorbent has a high porosity and high surface [16]. Other essential properties such as non-toxicity, abundancy, economic and environmental acceptability, and effectiveness in the adsorbing of different substances make zeolite more deserved to be developed as a prominent adsorbent. It has been approved by a wide range of literatures [16]. Clinoptilolite is one of the most abundant types of zeolite, which is applied extensively as an adsorbent in water purification and wastewater treatment due to its high selectivity and high thermal resistivity $[13,16]$. In the last decades, the modification of adsorbents has been considered by scientists who focused on the modification of adsorbents for its potential applications in groundwater treatment for the removal of various pollutants [1, 23].

Europhtal catalyst $\left(\mathrm{C}_{32} \mathrm{H}_{16-\mathrm{i}} \mathrm{N}_{8} \mathrm{Co}\left(\mathrm{SO}_{3} \mathrm{Na}\right)_{\mathrm{i}}\right)$, an industrial catalyst, is a blue liquid solution that contains both bis- and tris-sulfonated cobalt phthalocyanine complexes (LCPS30) as shown in Fig. S1 and Table S1 [1, 24, 25]. Generally, a catalyst solution comprising $200 \mathrm{ppm}$ of sulfonated cobalt phthalocyanine is utilized in the mercaptan removal process (Merox process) from hydrocarbons through its solution (combined with water and caustic soda solution) [26]. In the LPG treatment unit, at first, air is injected into the pre-heated caustic solution. Following this, the Merox catalyst is added to the caustic solution, after which is directed to the packed oxidizer tower in order to react with LPG. Finally, during the endothermic oxidation reaction, mercaptans are converted to disulphides. This catalyst in the wastewater is harmful to the environment due to the high COD content and the essence of cobalt as heavy metal. Moreover, the color of this catalyst causes error in laboratory analyses, which are carried out to assess the amount of dangerous chemicals to the environment in wastewater. Since this catalyst is widely employed in numerous oil and gas refineries globally; it is imperative to found an efficient and sustainable treatment process to separate and remove this catalyst from various wastewaters [1, 25].

As mentioned, zeolite is an abundant natural resource, and the existence of an immense number of active sites on the surface of nanoparticles leads to trapping various species [1]. For the reason that the enormous quantities of natural zeolite are readily accessible in the various areas of Iran, this material is considered as a highly cost-effective adsorbent compared to active carbon [27]. In fact, natural clinoptilolite mines are plentiful in Iran with a cost of lower than \$ 300 per ton. These ceramic adsorbents have increasingly become attractive for the purpose of water filtration over the last few decades [28].

Since polyaluminium chloride is widely used as a fairly economic coagulant, facilitating the water treatment process [15], this present study aims to modify natural zeolite by PAC in order to achieve the highest Europhtal catalyst removal efficiency for the first time. Not only is this novel approach able to remove Europhtal efficiently, but it also is considerably low cost, which makes this method applicable on industrial scales. Therefore, natural zeolite was improved with PAC as the ligand for the treatment of synthetic and real Europhtal wastewater. For the achievement of optimum operational parameters, the effects of independent factors such as initial Europhtal concentration, contact time, $\mathrm{pH}$ of the solution, and adsorbent dosage on process efficiency were investigated. Statistical analysis was performed by utilizing experimental data, and the results were obtained to achieve a predictive model and evaluate the precision. Kinetic and thermodynamic studies were accomplished to evaluate the adsorption capacity of adsorbents in synthetic wastewater. The equilibrium data have been analyzed using the Langmuir, Freundlich, Tempkin_Pyzhev, and Dubinin- Radushkevich isotherms. The kinetic data acquired from the experiments have been modelled by applying the pseudo-first and second-order, intraparticle diffusion and Elovich kinetic models to examine the mechanism of adsorption. Finally, at the best operating conditions, real wastewater of Merox unit (spent caustic wastewater) in the mercaptan removal unit of the third refinery, South Pars Gas Complex (SPGC), Assaluyeh, Iran, was treated using modified neutral zeolites.

\section{Materials and Methods}

\subsection{Materials}

The Europhtal 802 catalyst was purchased from Europhtal Company (blue liquid solution with a density near to $1,150 \mathrm{~kg} / \mathrm{m}^{3}$ ), and natural zeolite with the 500-mesh average particle size $(<25 \mu \mathrm{m})$ was supplied from Afrazand Company, Semnan, Iran. The real wastewater was obtained from the neutralization section of SPGC refinery while the $\mathrm{pH}$ was 13 and contaminated by catalyst solution with COD equal to 12,440 ppm (the characteristics have been shown in Table S2). The synthetic wastewater was prepared in double-distilled water. Ammonium sulfate with assay (alkalimetric) more than $99.5 \%$ was purchased from Merck Company, Germany, and polyaluminium chloride with $\mathrm{Al}_{2} \mathrm{O}_{3}$ equal to $30 \%$ was purchased from Taha Kimia Tajhiz Company, Iran. 


\subsection{Modification of Natural Zeolite}

First of all, to prepare the adsorbent, natural zeolite was immersed in concentrated hydrochloric acid, and after $7 \mathrm{~h}$, the solution was poured away. Then, the adsorbent was washed with distilled water until the $\mathrm{pH}$ of poured away water reached 3.8 (using Metrohm $\mathrm{pH}$ meter model-780). Afterward, the adsorbent was placed in the laboratory for $24 \mathrm{~h}$ at room temperature to dry completely. In the second step of adsorbent preparation, the adsorbent was added to $1 \mathrm{M}$ solution of ammonium sulfate, and it was stirred at 400 rpm for $4 \mathrm{~d}$. After mixing, the adsorbent was washed several times by distilled water, while the conductivity of the passing water through the adsorbent reached $30 \mu \mathrm{s} / \mathrm{cm}$. Eventually, the adsorbent was left in the laboratory for $24 \mathrm{~h}$ at room temperature. Then it was dried in an oven for $6 \mathrm{~h}$ at $100^{\circ} \mathrm{C}$.

Since natural zeolite which was modified as mentioned above had low efficiency in initial tests, it was decided that raw natural zeolite modifying should be reconsidered. After studying the numerous works of literature, it was found that polyaluminium chloride (PAC) is applied extensively as a well-known coagulant for treating wastewaters due to its effectiveness for treating a wide range of water from organic matter, color, and other pollutants at a rather low cost [15, 29]. Polyaluminium chloride can modify the surface properties of such adsorbents by improving electrostatic reactions to promote the aggregation of smaller particles into larger flocs $[15,29]$. Thus, polyaluminium chloride with the commercial name of PAC-SY and chemical formulation of $\left[\mathrm{Al}_{2}(\mathrm{OH})_{n} \mathrm{Cl}_{6-\mathrm{n}} \cdot \mathrm{YH}_{2} \mathrm{O}\right]_{z}$ was used as the ligand. For the modification process, natural zeolite was added to $8000 \mathrm{ppm}$ solution of polyaluminium chloride and was stirred at $600 \mathrm{rpm}$. Following this operation, the adsorbent was washed several times with distilled water until the $\mathrm{pH}$ of the passing water through the adsorbent increased from 3.85 to 4.75 , and the conductivity of the water was reduced from $7.9 \mathrm{~ms} / \mathrm{cm}$ to $46.5 \mu \mathrm{s} / \mathrm{cm}$. The adsorbent was dried overnight in the laboratory at room temperature and was oven-dried at $80^{\circ} \mathrm{C}$ for $1 \mathrm{~h}$.

\subsection{Batch Equilibrium Studies}

Batch-adsorption tests were conducted through stirring adsorbents with Europhtal solution in the ultrasonic water bath (Bandelin Sonorex, Germany) for a specified period in which the contact between wastewater and adsorbent led to the elimination of dye from solution (illustrated in Fig. S2). Before measuring the remaining dye concentration, the supernatants were purified to make sure that the samples were devoid of adsorbent grains. The concentration of residual dye in the wastewater was evaluated by monitoring the adsorbate changes via a UV-spectrophotometer (2800-DR, UV-Vis) at $664 \mathrm{~nm}$ of wavelength (the maximum extinction wavelength of absorbance) for Europhtal. The following equation was utilized to calculate the level of equilibrium adsorption of dye on the unit weight of the adsorbent, $\mathrm{q}_{\mathrm{e}}(\mathrm{mg} / \mathrm{g})$, was calculated by:

$$
q_{e=\frac{\left(C_{0}-C_{e}\right) V}{w}}
$$

where $\mathrm{C}_{0}, \mathrm{C}_{\mathrm{e}}$, and $\mathrm{V}$ represents the concentration of dye (mg/L) in liquid-phase at initial, the concentration of dye (mg/L) in liquid-phase at equilibrium, and volume of the solution (L), respectively. $\mathrm{W}$ is the weight of dry adsorbent (g). The dye removal percentage ( $\mathrm{R} \%)$ was determined as follows:

$$
R \%=\frac{C_{0-} C_{e}}{C_{0}} \times 100
$$

Then, the effects of $\mathrm{pH}$, Europhtal concentrations, and the amounts of adsorbent on dye adsorption were studied using the experimental conditions at different contact times. Based on the comparison with the calibration curve prepared in the same conditions, the concentration of the remained dye in different experimental conditions was calculated and the data were fitted into the following isotherms (Table S3): Langmuir (considering monolayer adsorption), Freundlich (regarding multilayer sorption on the sorbent), Temkin_Payzhev (assuming the adsorbent-adsorbate interaction) and Dubinin-Radushkevich (concerning multilayer adsorption) [7, 14, 17, 30-32] in order to describe the process and comparison of removal percentage.

\subsection{Batch Kinetic Studies}

The methods of kinetic experiments are mainly similar to those of equilibrium tests. The aqueous samples were collected at regular periods, and the concentrations of dye were measured in the same manner [11]. $\mathrm{q}_{\mathrm{t}}$ (mg/g) (the amount of adsorption at time $\mathrm{t}$ ) was calculated as follows:

$$
q_{t=\frac{\left(C_{0}-C_{t}\right) V}{W}}
$$

where $\mathrm{C}_{0}, \mathrm{C}_{\mathrm{t}}$, and $\mathrm{V}$ represents the concentration of dye (mg/L) in liquid-phase at initial, concentrations of dye (mg/L) in liquid-phase at any time and volume of the solution (L), respectively. $\mathrm{W}$ is the weight of dry adsorbent (g) [11].

Diverse kinetic models are used to determine the mechanism of Europhtal adsorption using experimental data. In this study, to examine the adsorption kinetic of Europhtal into modified zeolite, three simplified different kinetic models, including pseudo-first and pseudo-second-order, intraparticle diffusion, and Elovich were used to investigate the transport property of Europhtal from the solution into adsorbent [7, 33]. These models fundamentally consist of all adsorption steps such as external film diffusion, adsorption, and intra-particle diffusion [7]. Also, the Elovich model presume that there are no interactions between the adsorbed species [32, 33]. If each of the kinetic equations follows the adsorption process, the adsorption process's constants can be measured [17, 21, 34]. The kinetic equations are shown in Table S4.

\subsection{Central Composite Design (CCD)}

Using a series of pre-designed tests, it possible to simultaneously examine multiple factors for a particular response so that a special surface is considered for each element. The purpose of designing these tests is to determine the optimal operational process variables to achieve the maximum response. The diagrams used in this method are usually three-dimensional, and the effects of variables can be examined and described two by two against the response [2].

Central composite design (CCD) is a statistical method based on the multivariate nonlinear model applied extensively to optimize the operational variables of the process $[1,2,35,36]$. Moreover, 
it is utilized to designate the equations of the regression model and operational conditions from suitable experiments. Also, it is beneficial for investigating the interactions of various parameters that influence the process by performing the minimum number of tests simultaneously [1, 2, 38, 39]. The five-level CCD with 31 experiments was used to determine the optimum variables for the designed process using the statistical analysis software. The CCD was applied to fit a second-order model that needs a few number of tests for modelling [36-39].

The variations interval for operational variables were arranged at 2.0-11.0 for the $\mathrm{pH}$ (X1), 2-8 min for the contact time (X2), 0.005-0.035 g for the adsorbent amount (X3), and 4-30 mg/L for the Europhtal concentration (X4). Table S5 presents the experimental design points which includes $2^{\mathrm{n}}$ factorial points, $2 \mathrm{n}$ axial points, and $\mathrm{n}_{\mathrm{c}}$ central points as well as the results of the tests for the response variables. The CCD comprises $2 \mathrm{n}$ factorial runs (coded to the usual \pm notation), $2 \mathrm{n}$ axial runs $( \pm \mathrm{a}, 0,0, \ldots, 0),(0, \pm \mathrm{a}$, $0,0, \ldots, 0), \ldots,(0,0, \ldots, \pm \mathrm{a})$ and $\mathrm{n}_{\mathrm{c}}$ centre runs (six replicates, $0,0,0, \ldots, 0)$. The number of factors $n$ raises the number of runs to replicate a complete design indicated in Eq. (4) $[2,36]$.

$$
N=2^{n}+2 n+n_{c}
$$

To guess the residual error, replications in the central point are utilized. By considering the range of variable, a code is dedicate to each independent variable in the interval of $(-1,1)$. The code for low and high levels is -1 and +1 , respectively [38]. The location of each axial point has the distance of $\alpha$ from the centre and makes the design rotatable [1]. On the other hand, the amount of $\alpha$ belongs to the number of points in the factorial portion of the experimental design [38].

Substantially, the optimization process includes three main steps: (1) carrying out the designed experiments statistically, (2) the coefficients estimation in a mathematical model, and (3) response predicting and examining the satisfactoriness of the model. The second-order polynomial model generally could be used to approximate the effect of independency involving variables interaction as below $[1,2,19,36]$ :

$$
Y=\beta_{0}+\sum_{i=1}^{4} \beta_{i} x_{i}+\sum_{i=1}^{4} \beta_{i i} x_{i}^{2}+\sum_{i=1}^{4} \sum_{j=1}^{4} \beta_{i j} x_{i} x_{j}
$$

where Y represents the predicted response (measured removal percentage); Xi's are the designed variables ( $\mathrm{pH}$, sonication time, adsorbent amount, and Europhtal concentration) that are independent operational variables throughout the runs. $\beta_{0}$ is the intercept, $\beta_{\mathrm{i}}$ is the linear coefficient, $\beta_{\mathrm{ii}}$ and $\beta_{\mathrm{ij}}$ are the quadratic terms and the interaction coefficients, respectively $[1,2,19]$.

The analysis of variance (ANOVA) was conducted to evaluate the satisfactoriness of the second-order polynomial equation regression model for the response and gaining coefficients of regression. Furthermore, the determination coefficient $\left(R^{2}\right)$ was estimated to appraise the adequacy of the model and the lack of fit. The test of lack-of-fit (F-value) is applied to distinguish whether discrepancies between measured and expected values are related to random or systematic error. Therefore, the lack-of-fit test is utilized to compare the residual error and pure error of replicated design points [38].

\section{Results and Discussion}

\subsection{Characterization of Adsorbent}

In order to identify the morphology of the natural zeolite adsorbent particles, SEM analysis was performed using the low-vacuum SEM apparatus (VEGA ii, TESCAN, Czech). Fig. S4 reveals the pores and size distribution of natural zeolite particles which was obtained by the SEM analysis on micro scale. Considering the results of XRD analysis from Fig. S4, zeolite was found to be the clinoptilolite type $[17,41]$. Also, the measured amount of BET surface area, average pore diameter, and specific pore volume of raw natural zeolite particles have been presented in Table S6. Additionally, the obtained results from XRF analysis carried out over natural zeolite and modified by polyaluminium chloride have been shown in Tables S7 and S8. For the purpose of investigating the chemical properties of adsorbent FT-IR analysis was performed (Fig. S5 and S6). According to the Figures, the considerable difference in the spectrum peaks occurred between 400 and $1,000^{-1} \mathrm{~cm}$, implies that the adsorptive properties of adsorbent were modified.

\subsection{Optimization of Parameters}

In this study, the CCD pattern was applied to assess the major interaction of four independent variables. A total of 31 tests were designed to evaluate the coefficients for each of the models via regression analysis. The most significant effects and interactions (P-value), R-squared test for goodness-of-fit for the model, the degree of freedom (df), and the lack-of-fit test (F-value) analysis of variance was performed by statistical analysis software and has been reported in Table S9.

The p-values (probability value) less than 0.05 indicate the regression model has high significance and can be employed to predict the response function accurately and also, the F-values approximate the significance of each term. Using the statistical analysis software, data analysis expressed a predictive model for the removal percentage of Europhtal by the following equation [1, 40]:

$$
\begin{gathered}
R \%=65.5+1.539 X_{4}-1.2517 X_{1}^{2}+0.327 X_{2}^{2}-99.4 X_{2} X_{3}(6) \\
+0.1161 X_{2} X_{4}+33.19 X_{3} X_{4}
\end{gathered}
$$

Positive and negative signs in the Eq. (6) imply the synergistic and antagonistic effect of the variables, respectively [1].

The calculated values of $\mathrm{R}^{2}$ and $\mathrm{R}_{\text {adj }}^{2}$ (determination coefficient of adjustment) for the Europhtal removal percentage were 0.9696 and 0.9429 , respectively, that presents the validation of the trustworthy correspondence between the predicted and experimental values.

\subsection{Response Surface Methodology}

In the processes optimization contour plots of regression equation would be very helpful, inasmuch as they reveal the conditions of the reaction system and justify the optimality with valid accuracy in the next step of the design. Therefore, the three-dimensional response surface plots were illustrated to demonstrate the influence of interaction between effective independent variables on Europhtal removal percentage. Besides, the curvature natures of Fig. 1 shows 
the confirmed strong interaction among variables.

Fig. 1 ((a), (b), (c)) indicates the effect of $\mathrm{pH}$ and adsorbent dosage, $\mathrm{pH}$ and Europhtal concentration, and $\mathrm{pH}$ and time on Europhtal removal percentage, respectively. The $\mathrm{pH}$ of the solution has a substantial role in the Europhtal elimination and has an opposite correlation with removal percentage. The $\mathrm{pH}$ effect on Europhtal removal percentage was investigated in 2-11 pH range. These figures depict that the removal percentage considerably rose from solution $\mathrm{pH}$ of 2 to 4.25 followed by a gradual increase to $\mathrm{pH}$ of 6.7 and the declined steeply between the $\mathrm{pH}$ of 6.7 and 11, that is to say, $\mathrm{pH}$ affects active sites of the adsorbent and water structure [42]. The maximum Europhtal removal percentage was acquired at lower $\mathrm{pH}$, and this might be due to the increase in the electrostatic attraction between the surface positive functional groups of the zeolite adsorbent and hydroxyl groups of Europhtal, which is attributed to the rise of the $\mathrm{H}^{+}$ions in the wastewater [1, 21], Even though at higher $\mathrm{pH}$, the attraction of aromatic rings of Europhtal on the adsorbent surface decreases due to an increase in repulsive force, which is caused by the negative charge increasing on the adsorbent. That means the attraction between the adsorbent and hydroxyl groups of Europhtal would be less than that of between the solvent phase and hydroxyl groups of Europhtal [42]. Fig. 1 (b), (d), (e)) indicates the effect of adsorbent dosage on the removal percentage of Europhtal. The removal percentage of Europhtal was enhanced by raising the adsorbent dosage because of the increase in the active sites of the modified natural zeolite [43]. Also, the Europhtal removal decreased considerably at the lower amount of adsorbent due to the high ratio of Europhtal molecules compared to the empty sites of modified natural zeolite. In fact, the small ratio of Europhtal concentrations to non-occupied reactive modified
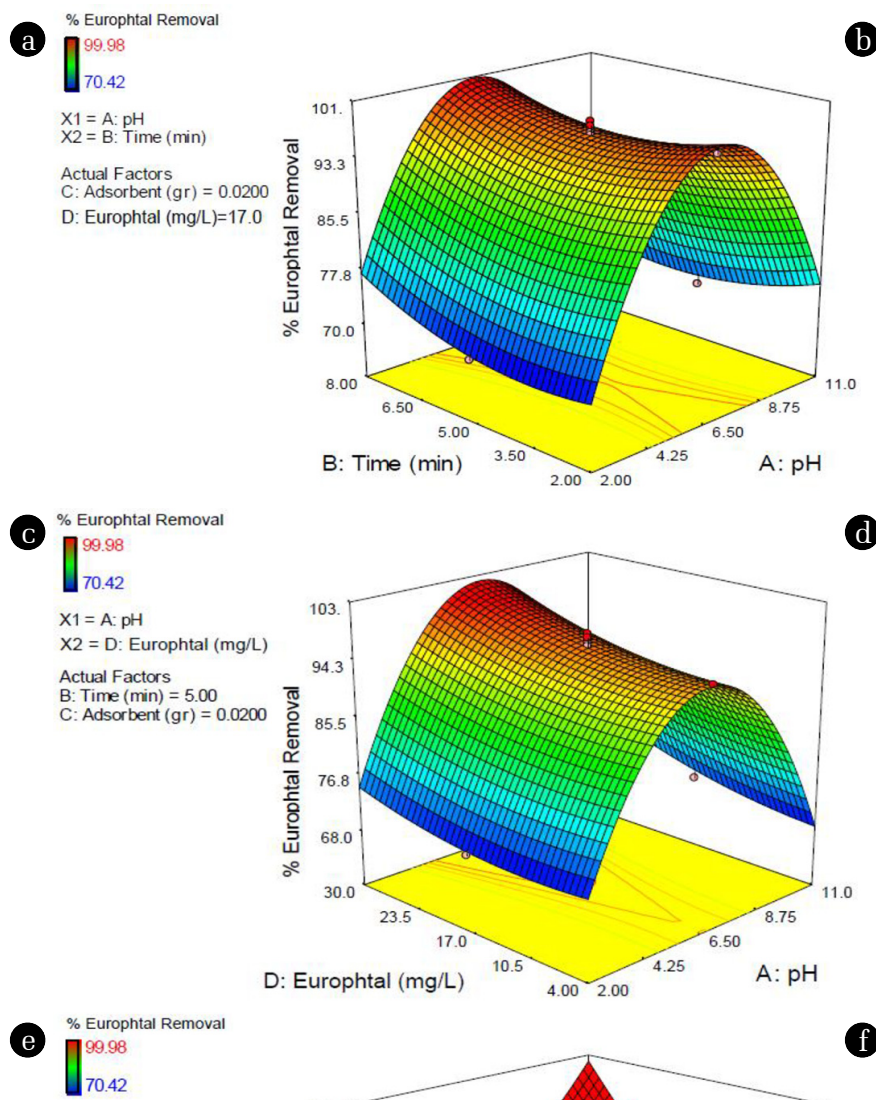

$\mathrm{X} 1=\mathrm{R} \cdot \mathrm{Time}(\mathrm{min})$ $\mathrm{X} 2=\mathrm{D}$ : Europhtal $(\mathrm{mg} / \mathrm{L})$ Actual Factors A. $\mathrm{pH}=6.50$
C: Adsorbent $(\mathrm{gr})=0.0200$

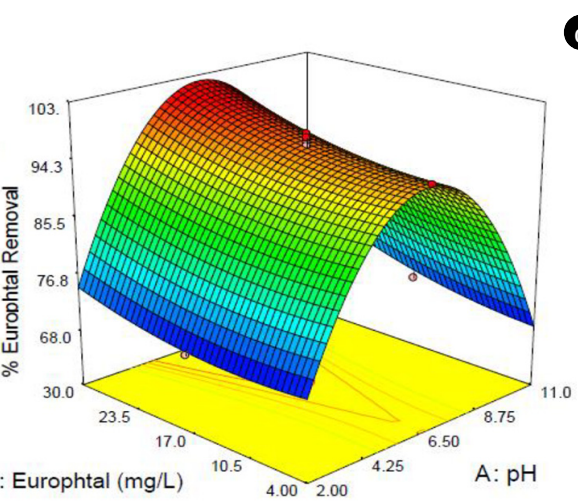

(d) $\%$

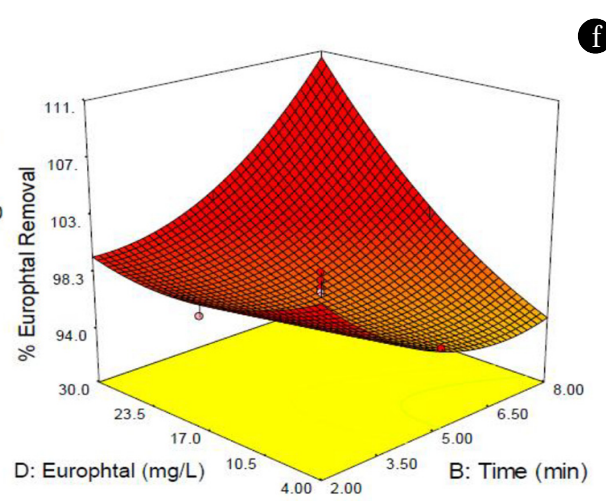

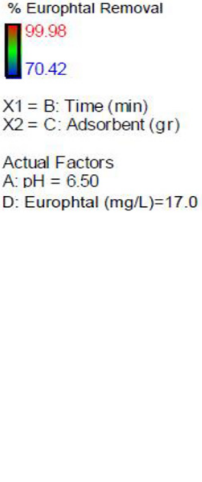

\% Europhtal Removal
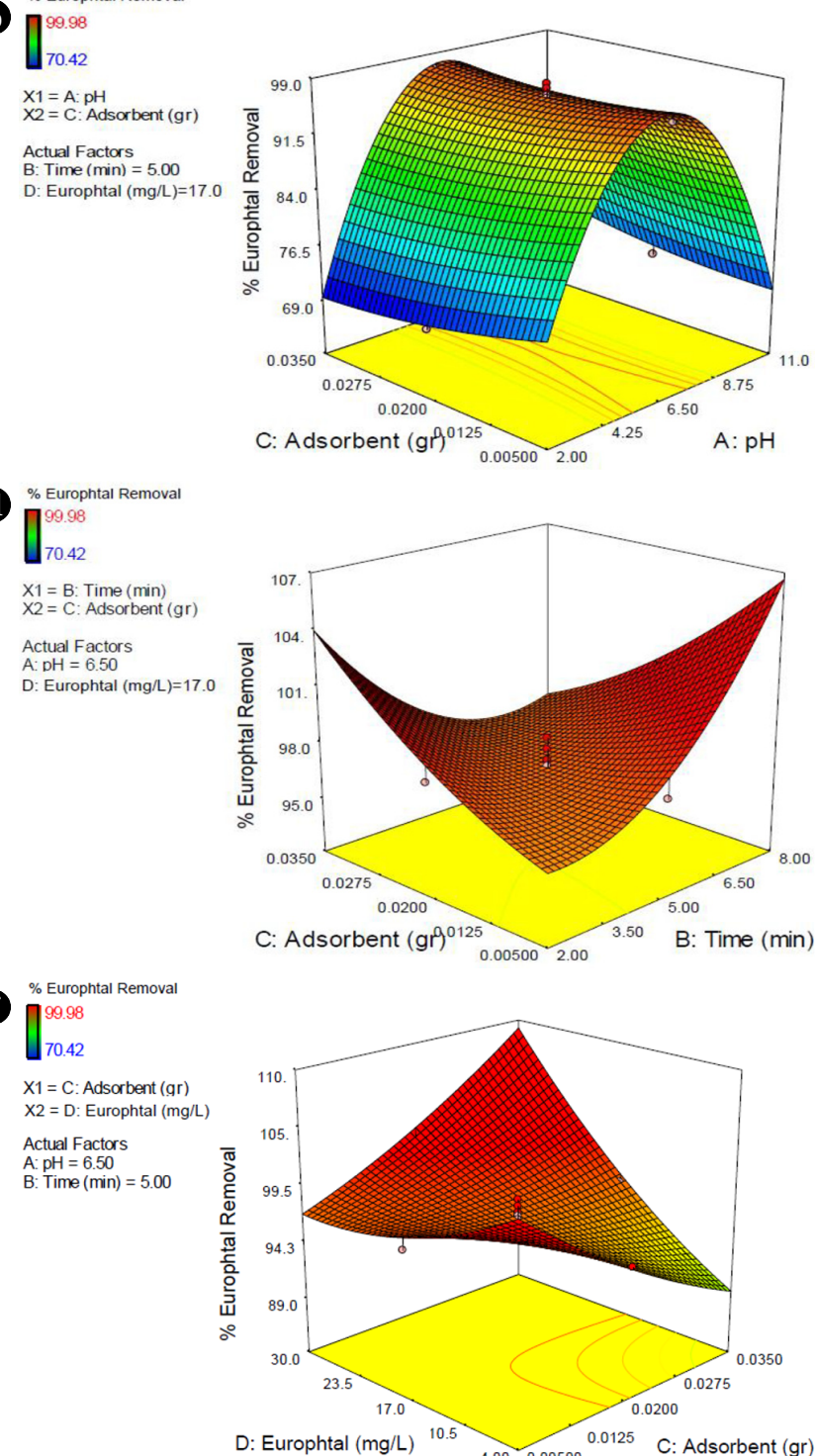

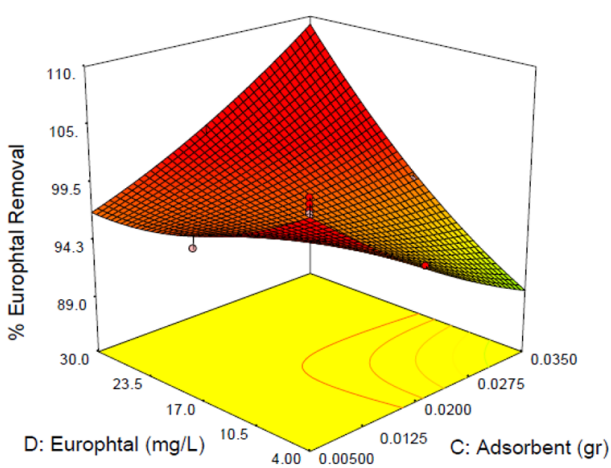

Fig. 1. Response surfaces for the Europhtal removal by modified zeolite (a): $X_{1} X_{2}(b): X_{1} X_{3}(c): X_{1} X_{4}(d): X_{2} X_{3}(e): X_{2} X_{4}(f): X_{3} X_{4}$. 
natural zeolite sites causes acceleration in Europhtal adsorption and enhancement in removal percentage [1]. Fig. 1 ((c), (e), (f)) represents the effect of initial Europhtal concentration in aqueous solution on the removal percentage of Europhtal in the adsorption process. The rise of Europhtal concentration decreases the removal percentage. The comparison with the low and high initial Europhtal concentration represents that they have the opposite trend. The small ratio of Europhtal concentrations to vacant active sites of modified natural zeolite enhances the adsorption rate of Europhtal, and consequently, removal percentage enhances [1, 21]. Of course, adsorption yield decreases at higher dye concentrations either due to the saturation of zeolite sites or repulsive force between Europhtal layers and residual bulk molecules [1, 2].

Fig. 1 ((a), (d), (e)) represents the alterations trend of sonication time against the amount of adsorbent, $\mathrm{pH}$, dye concentration, and Europhtal removal percentage. After 8 min of contact time, any considerable change was not observed in Europhtal adsorption onto the modified zeolite surface. This could be due to the saturation of modified zeolite sites by Europhtal molecules [21].

The high rate of adsorption efficiency at initial contact time is caused by the availability of enough active surface areas of the adsorbent for adsorption of Europhtal [21].

\subsection{Optimization of CCD by Desirability Function (DF)}

After preparation of the samples at designed values (time between 2 to $8 \mathrm{~min}$, adsorbent amounts from 0.005 to $0.035 \mathrm{~g}$, $\mathrm{pH}$ between 2.0 to 11.0, and Europhtal concentration from 4 to $30 \mathrm{mg} / \mathrm{L}$ ), the desirability profiles for independent factors with predicted values were obtained by using the statistical analysis software. The procedure of optimization and the plots have been shown in Fig. 2. According to numerical optimization in the designation of the optimum responses, the predicted values are chosen to determine the desirability function (DF) for the dependent variables [1, 2]. The Derringer's desirability function is defined as a criterion to optimize the multiple response processes, and the value of $\mathrm{D}$ depends on the closeness of the response values to the target values [37, 38]. The amount of $\mathrm{D}$ varies from 0 (completely undesirable) to 1 (entirely desirable). It is evident that to achieve the high-efficiency process optimization, the global function (D) ought to be maximized. In fact, the maximized desirable value has a relationship with the best selection of variables and interaction between them. [1, 2,
37, 39].

The CCD design matrix maximum removal (> 99.9\%) was attained at the optimum conditions as a $\mathrm{pH}$ of 6.7, sonication time of $8 \mathrm{~min}, 0.035 \mathrm{~g}$ of adsorbent, and $30 \mathrm{mg} / \mathrm{L}$ concentration of Eoruphtal. The validation of experiments was examined at the optimized response value of parameters, and the results were well correspondent with the data acquired from optimization analysis by CCD.

\subsection{Efficiency of Adsorbent}

After the optimization of useful operational parameters, to estimate the adsorbent efficiency in wastewater treatment, the level of COD reduction was measured at optimum conditions. The first test was accomplished with a standard aqueous solution of Europhtal at optimum condition; the COD value was decreased from 13,500 ppm to 13 ppm, which shows a $99.9 \%$ reduction in COD. The second test was done with real wastewater of SPGC refinery (spent caustic); COD value was decreased from 12,440 ppm to $823 \mathrm{ppm}$ indicating a $93.4 \%$ reduction in COD while the wastewater contained 2,800 ppm concentration of $\mathrm{Na}_{2} \mathrm{~S}$ and $2000 \mathrm{ppm}$ concentration of RSNa. For comparison result of this research (employing modified natural zeolite) with results of Ghaedi et al. [1]; (utilizing modified activated carbon) for Europhtal removal, it can be concluded that the efficiency of modified natural zeolite is near to modified activated carbon. In fact, in the research of Ghaedi et al; [1] for the treatment of synthetic wastewater at optimum conditions: $0.03 \mathrm{~g}$ modified activated carbon with (1E, 2E)-1, 2-bis (pyridin-4-ylmethylene) hydrazine (M), $2 \mathrm{~min}$ of time, $30 \mathrm{mg} / \mathrm{L}$ Europhtal, at $\mathrm{pH} 7$ and $0.03 \mathrm{~g}$ modified activated carbon with (1E, 2E)-1, 2-bis (pyridin-3-ylmethylene) hydrazine (SCH-4), 5 min of time, $30 \mathrm{mg} / \mathrm{L}$ Europhtal, at $\mathrm{pH} 7$ the obtained removal percentages were more than $98 \%$ while in this research, at the similar condition of wastewater (30 mg/L Europhtal), $8 \mathrm{~min}$ of time, $\mathrm{pH}$ 6.7, 0.035 $\mathrm{g}$ of modified natural zeolite with PAC, the maximum Europhtal removal equaled $99.98 \%$. Also, in comparison to the maximum experimental adsorption capacity of modified natural zeolite, which was $687.51 \mathrm{mg} / \mathrm{g}$, the maximum experimental adsorption capacity of modified activated carbon was 56.69 and $17.84 \mathrm{mg} / \mathrm{g}$ for AC-M and AC-SCH-4, respectively (summarized in Table S10) [1, 44, 45]. Finally, a 99.9\% reduction in COD for the treatment of standard aqueous solution and a $93.4 \%$ reduction in COD for the real waste-

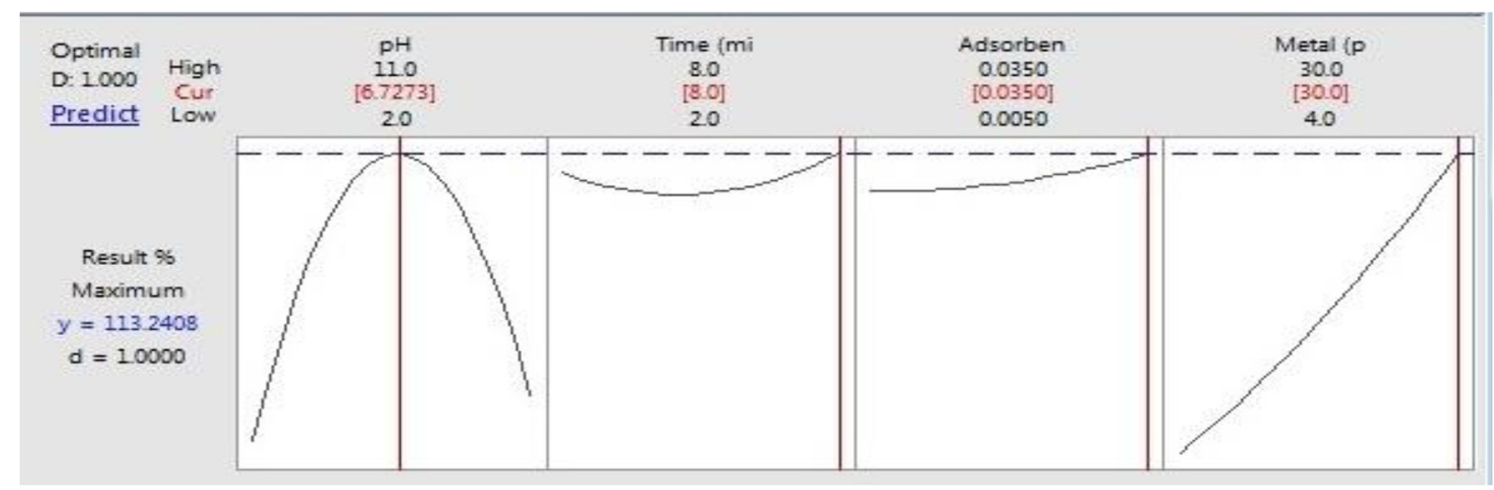

Fig. 2. Desirability profiles for removal of Europhtal by zeolite modified with PAC ligand. 
water treatment indicate that modified natural zeolite with PAC as an economic and low-cost adsorbent with minimum consumption of materials has high potency in the elimination of contaminations.

\subsection{Adsorption Isotherms}

In order to investigate the isotherm and kinetics of the process, some synthetic solutions of Europhtal with the concentration of $5-50 \mathrm{mg} / \mathrm{L}$ were prepared, and $\mathrm{pH}$ was set at 6.7 . These synthetic solutions were contacted with $0.035 \mathrm{~g}$ of the modified adsorbent for $8 \mathrm{~min}$ in the ultrasonic water bath, and after that, the data were analyzed.

Various standard isotherm equations; Freundlich, Langmuir, Tempkin_Payzhev, and Dubinin-Radushkevich were applied to explain the equilibrium features of Europhtal adsorption. The linearized form of isotherms models and their constants parameters that have been obtained from the slope and intercept of the plots (were shown in Fig. 3 ((a)-(d) at $310.15 \mathrm{~K}$ ) have been given in Table $1[7,11,32]$. The correlation coefficient $\left(R^{2}\right)$ in Table 1, demonstrates that the Freundlich model has the most satisfying fit with the experimental data and the Langmuir isotherm model has the least correspondence. However, both Dubinin- Radushkevich and Tempkin_Payzhev isotherm models have quite adequate fit with the experimental data, the correlation coefficient of these models was less than Freundlich. According to principle, the Freundlich adsorption isotherm is an experiential
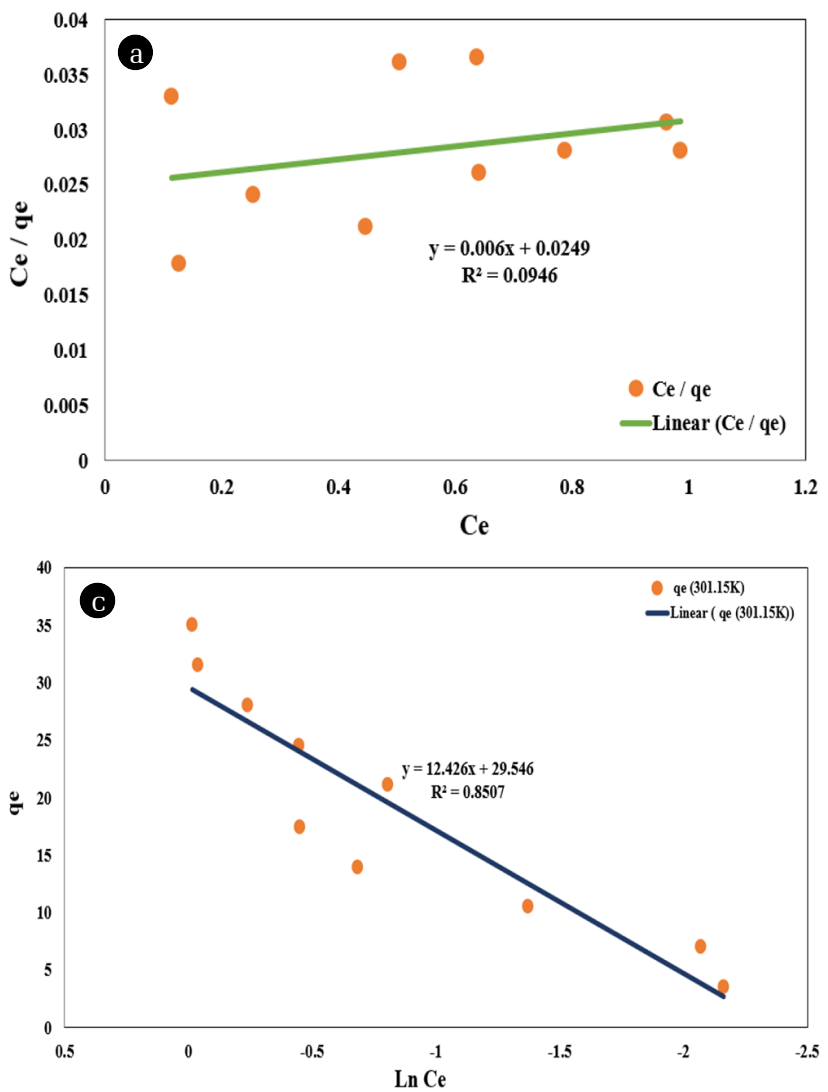

method for adsorbent, which has an uneven active surface and can be applied for the single solutes adsorption in a fixed range of concentration [11].

Table 1. Calculated Isotherm Parameters and Correlation Coefficients for the Adsorption of Europhtal at Different Initial Dye Concentration: $5-50 \mathrm{mg} / \mathrm{L}$, Adsorbent $=0.035 \mathrm{~g}$, $\mathrm{pH}=6.7$ and $\mathrm{T}=301.15 \mathrm{~K}$

\begin{tabular}{lcc}
\hline Isotherm & Parameter & The values at 301.15 K \\
\hline \multirow{2}{*}{ Langmuir } & $\mathrm{q}_{\mathrm{m}}\left(\mathrm{mg} \mathrm{g}^{-1}\right)$ & 166.667 \\
& $\mathrm{~K}_{\mathrm{a}}\left(\mathrm{L} \mathrm{mg}^{-1}\right)$ & 0.241 \\
& $\mathrm{R}^{2}$ & 0.095 \\
Freundlich & $\mathrm{n}$ & 1.122 \\
& $\left.\mathrm{~K}_{\mathrm{f}}(\mathrm{mg} / \mathrm{g}) \cdot(\mathrm{L} / \mathrm{mg})^{1 / \mathrm{n}}\right)$ & 33.172 \\
& $\mathrm{R}^{2}$ & 0.915 \\
Tempkin & $\mathrm{B}_{1}$ & 12.426 \\
& $\mathrm{~K}_{\mathrm{T}}\left(\mathrm{L} \mathrm{mg}^{-1}\right)$ & 10.781 \\
& $\mathrm{R}^{2}$ & 0.851 \\
Dubinin- & $\beta\left(\mathrm{mol}^{2} \mathrm{KJ}^{-2}\right)$ & $6^{*} 10^{-8}$ \\
Radushkevich & $\mathrm{q}_{\mathrm{m}}\left(\mathrm{mg} \mathrm{g}^{-1}\right)$ & 32.921 \\
& $\mathrm{E}\left(\mathrm{KJ} \mathrm{mol}^{-1}\right)$ & 2886.7513 \\
& $\mathrm{R}^{2}$ & 0.8903
\end{tabular}
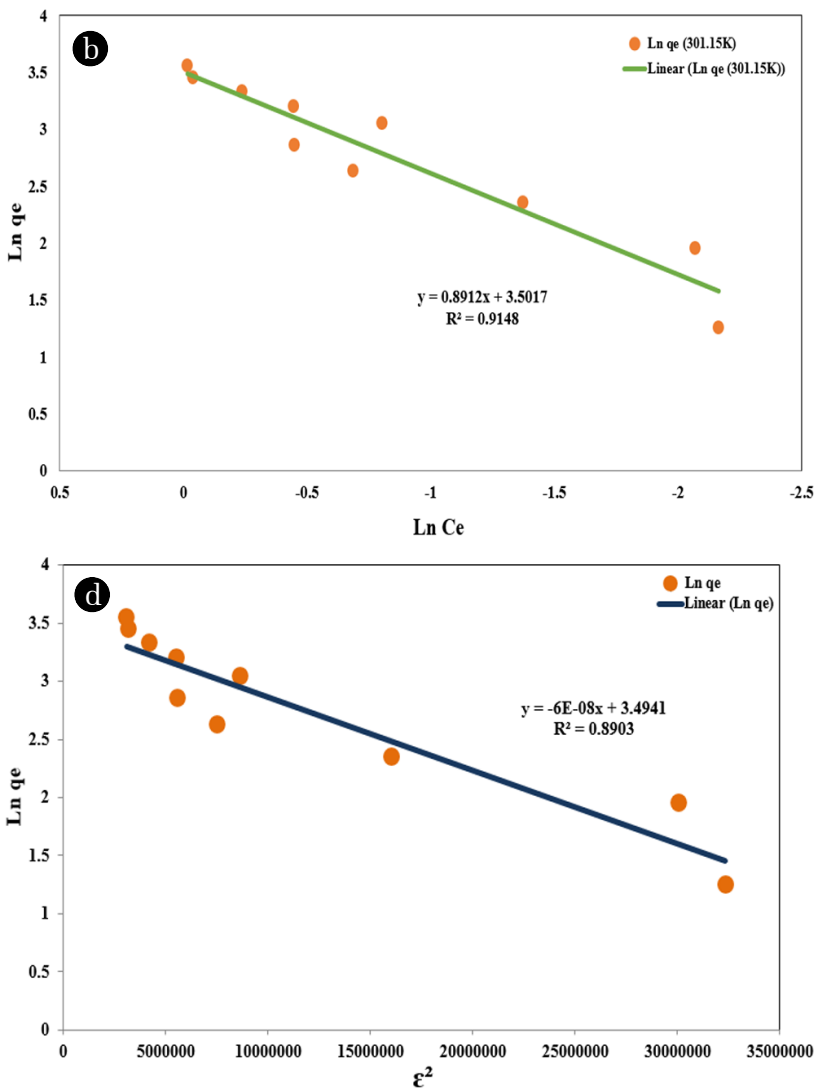

Fig. 3. Isotherm plots for Europhtal adsorption onto modified zeolite $(\mathrm{pH}=6.7$, Europhtal initial concentration: 5-50 mg/L, contact time: 8 min, adsorbent: $0.035 \mathrm{~g}$ and $\mathrm{T}=301.15 \mathrm{~K}$ ), (a): Langmuir (b): Freundlich (c): Tempkin-Pyzhev (d): Dubinin - Radushkevich. 
Regarding the value of $\mathrm{n}$ being more than one, it is inferred that the proposed process is favorable and the adsorbent has a tendency towards the Europhtal adsorption. Moreover, the Freundlich isotherm demonstrates that the adsorption is multilayer, and the adsorption energy decreases by saturation of adsorbent sites.

\subsection{Adsorption Kinetics}

To investigate the processes mechanism such as mass transfer, the rate of adsorption, and chemical reaction, a suitable rate model should be applied for the analysis of the kinetic data [1]. As mentioned above, the kinetic of Europhtal removal by modified zeolite was studied utilizing four different models as pseudo-first and second-order, intraparticle diffusion, and Elovich models. The linear form of each kinetic model has been presented in Table 2. The rate constant $(\mathrm{k})$ and $\mathrm{q}_{\mathrm{e}}$ of pseudo-first and second-order models have been determined from slope and intercept of plotting $\left(\mathrm{q}_{\mathrm{e}}-\mathrm{q}_{\mathrm{t}}\right)$ vs. time and $\mathrm{t} / \mathrm{q}_{\mathrm{t}}$ vs. time graphs, respectively [7, 11]. Similarly, the rate constant $\left(\mathrm{k}_{\mathrm{ip}}\right)$ and the intercept (which is relevant to the thickness of the boundary layer) of intraparticle diffusion model have been obtained from the slope and intercept of the plot of qt vs. $\mathrm{t}^{0.5}[32,33]$. In like manner, the Elovich model parameters $\alpha$ (initial adsorption rate) and $\beta$ (desorption coefficient) have been calculated from the slope and intercept of plotting qt versus ln t. [32, 33]. The kinetic models plotted diagrams are presented in Fig. 4 (a)-(d) and the values of the parameters $k_{1}, k_{2}, q_{e}, k_{i p}, C$, $\alpha$, and $\beta$ at optimized condition were calculated and shown in Table 2. The criteria of the model's applicability is established on the correlation coefficient $\left(\mathrm{R}^{2}\right)$ [1]. Considering the reported $\mathrm{R}^{2}$ values that have been shown in Table 2, compared to intraparticle diffusion and Elovich models, both pseudo-first and second-order kinetics have high accuracy and the adsorption system's behavior is best predicted by pseudo-second-order equation, which means that chemisorption valency forces have a significant role in the rate-controlling step. Also, it was observed that the

Table 2. Kinetic Parameters and Correlation Coefficients Values for the Adsorption of Europhtal at Dye Concentration $=30 \mathrm{mg} / \mathrm{L}$, $\mathrm{pH}=6.7$ and Adsorbent $=0.035 \mathrm{~g}$

\begin{tabular}{lcc}
\hline Model & Parameter & Value of parameters \\
\hline Pseudo first & $\mathrm{K}_{1}\left(\mathrm{~min}^{-1}\right)$ & 0.0402 \\
order kinetic & $\mathrm{q}_{\mathrm{e}}\left(\mathrm{mg} \mathrm{g}^{-1}\right)$ & 0.0674 \\
& $\mathrm{R}^{2}$ & 0.9071 \\
\hline \multirow{2}{*}{$\begin{array}{c}\text { Pseudo second } \\
\text { order kinetic }\end{array}$} & $\mathrm{K}_{2}(\mathrm{~g})\left(\mathrm{mg}^{-1} \mathrm{~min}^{-1}\right)$ & 2.9411 \\
& $\mathrm{q}_{\mathrm{e}}\left(\mathrm{mg} \mathrm{g}^{-1}\right)$ & 0.7389 \\
Intraparticle & $\mathrm{R}^{2}$ & 0.9998 \\
diffusion & $\mathrm{C}\left(\mathrm{mg} \mathrm{g}^{-1} \mathrm{~min}^{-1 / 2}\right)$ & 0.0105 \\
& $\alpha\left(\mathrm{mg} \mathrm{g}^{-1} \mathrm{~min}^{-1}\right)$ & 0.6719 \\
Elovich & $\beta\left(\mathrm{g} \mathrm{mg}^{-1} \mathrm{~min}^{-1}\right)$ & 0.8282 \\
\hline & $\mathrm{R}^{2}$ & $9.08697 * 10^{13}$ \\
\hline
\end{tabular}
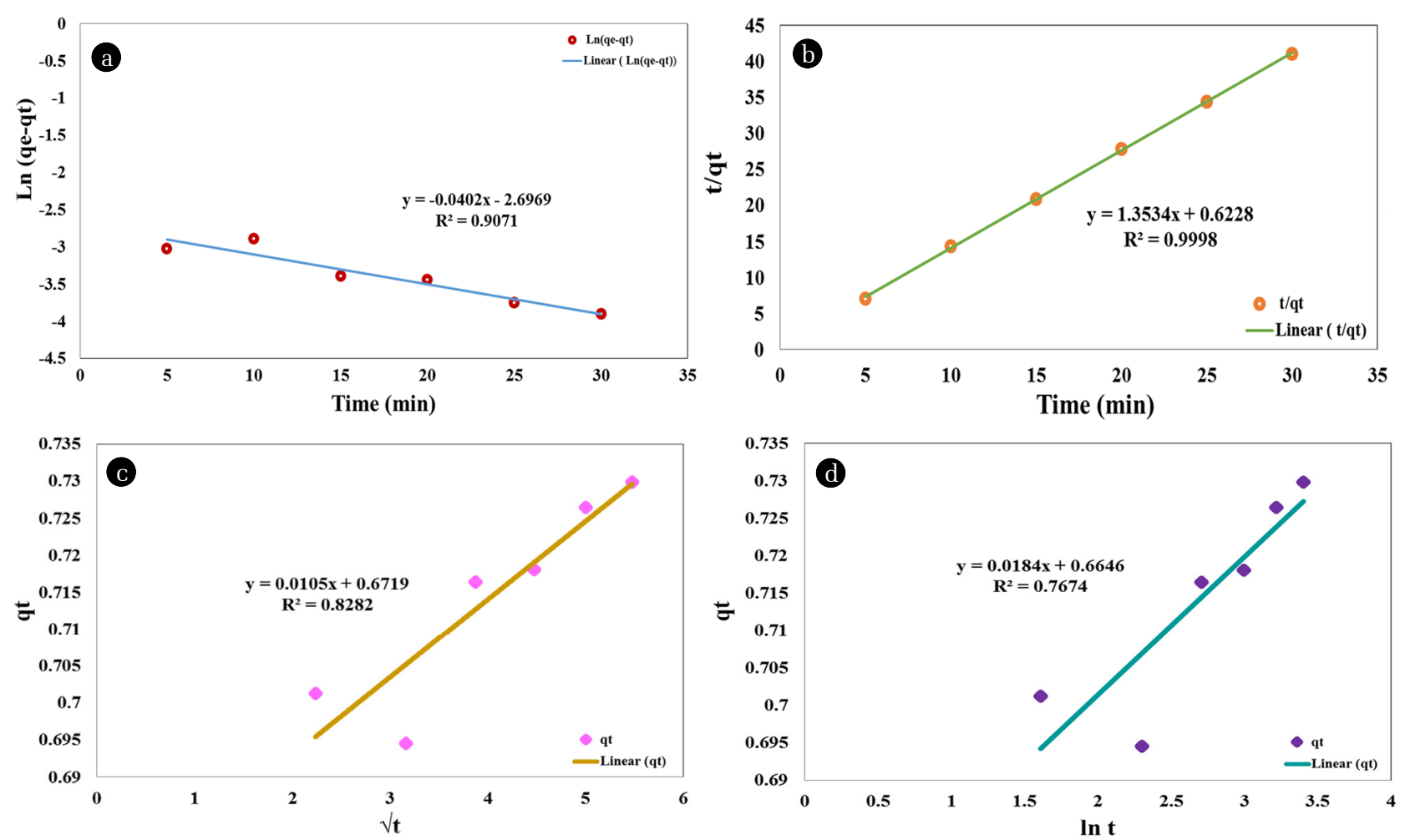

Fig. 4. Adsorption kinetic plots for the adsorption of Europhtal onto modified natural zeolite $(\mathrm{pH}=6.7$, Europhtal initial concentration: 30 mg/L, time: 5-30 min and adsorbent: 0.035 g), (a): Pseudo-first-order (b): Pseudo-second-order (c): Intraparticle diffusion (d): Elovich. 
half-life time of Europhtal adsorption on the adsorbent was too low, which confirms that the adsorption rate depends on the amount of modified natural zeolite.

\subsection{Adsorption Mechanism}

The mechanism of the adsorption could be related to the ion exchange or complexation between the zeolite active surface and hydroxyl groups of Europhtal [42]. According to Fig. 5, the process includes rapid adsorption for a shorter duration in the initial stage and slow adsorption for a longer period, which is done in three steps. The first part of the diagram is the fast adsorption step (from 5-15 $\mathrm{min}$ ) is attributed to the Europhtal diffusion step into the adsorption surface of modified natural zeolite. The second part (from 15-20 min) is related to intra-particle diffusion, and the third part (from 20-30) is Europhtal diffusion into the smaller pores of modified zeolite at equilibrium time. As can be seen in this figure, at first, due to the existence of none-occupied sites that cause an increase in Europhtal gradient concentration (between solution and adsorbent surface) and chemisorption involving valence forces through exchange or sharing of an electron between the adsorbent and Europhtal, adsorption amount raises with increasing contact time. After the determined time, the saturation of adsorption sites by dye molecules occurs and causes an increase in removal percentage and the diagram's slope will become constant.

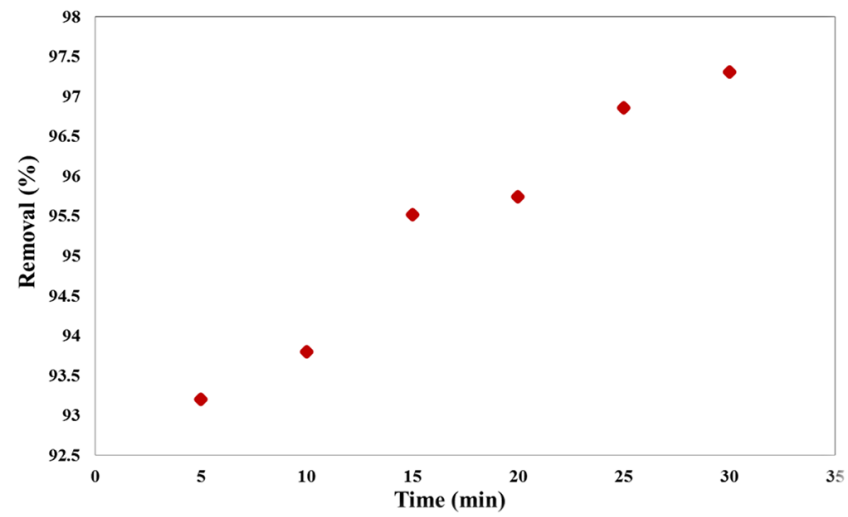

Fig. 5. The changes in the trend of Europhtal removal percentage over time.

\subsection{Adsorption Thermodynamics}

In order to assess the thermodynamic parameters and explain the spontaneity for the adsorption of Europhtal using modified zeolite, the adsorption thermodynamic studies were accomplished at optimum conditions and four different temperatures of 283.15, 301.15, 313.15, and 328.15 K. The changes in Gibbs free energy $\left(\Delta \mathrm{G}^{\circ}\right)$ of adsorption system and its relationship between enthalpy
$\left(\Delta \mathrm{H}^{\circ}\right)$ and entropy $\left(\Delta \mathrm{S}^{\circ}\right)$ were calculated using the following equations:

$$
\begin{gathered}
\Delta G^{\circ}=-R T \ln K c \\
K c=q_{e} / C_{e} \\
\Delta G^{\circ}=\Delta H^{\circ}-T \Delta S^{\circ}
\end{gathered}
$$

where $\mathrm{R}$ is the ideal gas constant $(8.314 \mathrm{~J} / \mathrm{mol} \mathrm{K}), \mathrm{K}_{\mathrm{c}}$ represents the equilibrium constant (the ratio of the Europhtal concentration in adsorbent and wastewater), and $\mathrm{T}$ represents the temperature in Kelvin. The average standard enthalpy change $\left(\Delta \mathrm{H}^{\circ}\right)$ is acquired from the Van't Hoff equation [7, 11, 16, 21-23].

$$
\ln K c=-\frac{\Delta H^{\circ}}{R T}+\frac{\Delta S^{\circ}}{R}
$$

According to the above equation, the thermodynamic functions of $\left(\Delta \mathrm{H}^{\circ}\right)$ and $\left(\Delta \mathrm{S}^{\circ}\right)$ can be obtained via plotting a graph between ln (Kc) and 1/T from the slope and intercept of the linear Van't Hoff equation, respectively [7, 11]. The results have been listed in Table 3.

As can be found from Table 3 , the $K_{c}$ values increase as the temperature rises, indicating the endothermic essence of the adsorption process [22]. The rise in $K_{\mathrm{c}}$ values implies that the forward rate of the process is considerably higher than the reverse rate. The positive standard enthalpy change $\left(\Delta \mathrm{H}^{\circ}\right)$ verifies that the interaction of adsorption is endothermic, which is consuming energy during the procedure and the negative standard free energy change $\left(\Delta \mathrm{G}^{\circ}\right)$ demonstrates that the adsorption is spontaneous and more favorable at a higher temperature [22]. It is probably due to the increase in Europhtal molecules dynamism in the solution by temperature increasing. Also, the positive standard entropy change $\left(\Delta S^{\circ}\right)$ shows that the adsorption is a spontaneous process due to randomness increases at the solid/liquid interface in the course of the Europhtal adsorption onto modified zeolite.

\section{Conclusions}

In this research, clinoptilolite (a type of natural zeolite) was modified by PAC ligand to be applied as an effective, eco-friendly, and low-cost adsorbent in order to investigate the elimination of sulfonated cobalt phthalocyanine catalyst (Europhtal) from the synthetic and real wastewater of the third refinery of South Pars Gas Company (SPGC), Iran. For achievement of the optimum operational parameters, the effects of independent factors such as initial Europhtal con-

\begin{tabular}{|c|c|c|c|c|c|c|c|c|c|}
\hline \multicolumn{4}{|c|}{$\mathbf{K}_{\mathrm{c}}$} & \multicolumn{4}{|c|}{$\Delta \mathrm{G}^{\circ}(\mathrm{j} / \mathrm{mol})$} & \multirow{2}{*}{$\Delta \mathbf{H}(\mathbf{j} / \mathrm{mol})$} & \multirow{2}{*}{$\Delta \mathrm{S}(\mathrm{j} / \mathrm{mol} \mathrm{K})$} \\
\hline 283.15K & 301.15K & 313.15 & 328.15 & 283.15K & 301.15K & 313.15 & 328.15 & & \\
\hline 9.381 & 35.265 & 50.658 & 68.725 & $-5,270.04$ & $-8,920.68$ & $-10,219.10$ & $-11,540.76$ & $34,317.70$ & 141.34 \\
\hline
\end{tabular}
centration, contact time, $\mathrm{pH}$ of the solution, and adsorbent dosage on process efficiency were investigated and the optimal parame-

Table 3. Thermodynamic Parameters for the Adsorption Europhtal 
ters were $30 \mathrm{mg} / \mathrm{L}, 8 \mathrm{~min}, 6.7,0.035$ g, respectively. Kinetic and thermodynamic studies were accomplished to evaluate the adsorption capacity of adsorbents in synthetic wastewater at $301.15 \mathrm{~K}$.

The obtained results show that a 99.9\% reduction in COD for the treatment of standard aqueous solution and a $93.4 \%$ reduction in COD for the real wastewater treatment indicating that modified natural zeolite with PAC has high potency in the elimination of contaminations.

Adsorption isotherm data were fitted to the Freundlich model in that it has a higher correlation coefficient in comparison with other models at the studied temperature $\left(\mathrm{R}^{2}=0.915\right)$. The stain removal kinetic data obeyed the pseudo-second-order rate kinetic model $\left(R^{2}=0.9998\right)$. The results obtained from thermodynamic quantities such as $\Delta \mathrm{G}^{\circ}, \Delta \mathrm{H}^{\circ}$, and $\Delta \mathrm{S}^{\circ}$ presented that the adsorption is spontaneous and has an endothermic essence. Considering the acquired results from this research, the removal of Europhtal from wastewater is practicable.

\section{Nomenclature}

$\mathrm{C}_{0} \quad$ Liquid-phase concentration of dye at initial (mg/L)

$\mathrm{C}_{\mathrm{e}} \quad$ Liquid-phase concentration of dye at equilibrium (mg/L)

$\mathrm{C}_{\mathrm{t}} \quad$ Liquid-phase concentration of dye at any time $\mathrm{t}(\mathrm{mg} / \mathrm{L})$

COD Chemical oxygen demand

DF Desirability function

K Rate constant

Kc Eequilibrium constant

PAC Polyaluminium Chloride

$\mathrm{q}_{\mathrm{e}} \quad$ Amount of adsorption at equilibrium (mg/g)

$\mathrm{q}_{\mathrm{t}} \quad$ Amount of adsorption at any time $\mathrm{t}(\mathrm{mg} / \mathrm{g})$

$\mathrm{R}$ Removal percentage

$\mathrm{R}$ Uuniversal gas constant $(\mathrm{J} / \mathrm{mol} \mathrm{K})$

$\mathrm{R}^{2} \quad$ Determination coefficient

$\mathrm{T}$ Temperature (Kelvin)

$\mathrm{V}$ Volume of solution (L)

w Weight of dry adsorbent (g)

$\mathrm{X}_{\mathrm{i}}$ 's Independent variables

$\mathrm{X}_{1} \quad \mathrm{pH}$

$\mathrm{X}_{2}$ Time

$\mathrm{X}_{3}$ Adsorbent amount (g)

$\mathrm{X}_{4} \quad$ Europhtal concentration (mg/L)

$\mathrm{Y}$ Predicted response (removal percentage)

\section{Greek alphabets}

$\beta_{0} \quad$ Model constant

$\beta_{\mathrm{i}} \quad$ Linear coefficient

$\beta_{\text {ii }} \quad$ Quadratic coefficient

$\beta_{\mathrm{ij}} \quad$ Cross-product coefficient

$\Delta \mathrm{G}^{\circ}$ Gibbs free energy

$\Delta \mathrm{H}^{\circ}$ Eenthalpy

$\Delta S^{\circ}$ Eentropy

\section{Acknowledgment}

The authors would like to acknowledge the third refinery laboratory of South Pars Gas Complex (SPGC), for its support.

\section{Author Contributions}

A.G. (M.Sc. graduate) designed and carried out the all experiments, B.A (B.Sc. graduate) interpreted the experiments and wrote the paper, M.A (Ph.D. Assistant professor) supervised the whole work and revised the manuscript.

\section{References}

1. Ghaedi M, Alam barakat E, Asfaram A, Mirtamizdoust B, Bazrafshan AA, Hajati S. Efficient adsorption of Europhtal onto activated carbon modified with ligands (1E,2E)-1,2-bis(pyridin-4-ylmethylene)hydrazine (M) and (1E,2E)-1,2-bis(pyridin-3-ylmethylene)hydrazine (SCH-4); response surface methodology. RSC AdV. 2015;5:42376-42387.

2. Roosta M, Ghaedi M, Daneshfar A, Darafarin S, Sahraei R, Purkait MK. Simultaneous ultrasound-assisted removal of sunset yellow and erythrosine by ZnS:Ni nanoparticles loaded on activated carbon: optimization by central composite design. Ultrason. Sonochem. 2014;21:1441-1450.

3. Jamee R, Siddique R. Biodegradation of Synthetic Dyes of Textile Effluent by Microorganisms: An Environmentally and Economically Sustainable Approach. Eur. J. Microbiol. Immunol. 2019;9:114-118.

4. Rehman R, Muhammad SJ, Arshad M. Brilliant green and acid orange 74 dyes removal from water by Pinus roxburghii leaves in naturally benign way: an application of green chemistry. J. Chem. 2019;2019:1-10.

5. Katheresan V, Kansedo J, Lau SY. Efficiency of various recent wastewater dye removal methods: A review. J. Environ. Chem. Eng. 2018;6:4676-4697.

6. Khan S, Malik A. Environmental and Health Effects of Textile Industry Wastewater. In: Malik A., Grohmann E., Akhtar, eds. Environmental Deterioration and Human Health. Springer, Dordrecht; 2014. p. 55-71.

7. Kismir Y, Aroguz AZ. Adsorption characteristics of the hazardous dye Brilliant Green on Saklıkent mud. Chem. Eng. J. 2011;172:199-206.

8. Davoudi M, Samieirad S, Mottaghi HR, Safadoost AR. The main sources of wastewater and sea contamination in the South Pars natural gas processing plants: Prevention and recovery. J. Nat. Gas Sci. Eng. 2014;19:137-146.

9. Lee AH, Nikraz H. BOD:COD Ratio as an Indicator for Pollutants Leaching from Landfill. J. Clean Energy Technol. 2014;2:263-266.

10. Rezazadeh M, Baghdadi M, Mehrdadi N, Abdoli MA. Adsorption of crystal violet dye by agricultural rice bran waste: Isotherms, kinetics, modeling and influencing factors. Environ. Eng. Res. 2021;26:200128.

11. Masitah H, Bassim HH, Latif AA, Zulfakar M, Naimah I, Salwa MZM. Low Cost Removal of Reactive Orange 16 Dye using Cross-linked Chitosan/oil Palm Ash Composite Beads. J. Appl. Sci. 2011;11:2292-2298.

12. Chakraborty S, Mukherjee A, Das S, Maddela NR, Iram S, Das 
P. Study on isotherm, kinetics, and thermodynamics of adsorption of crystal violet dye by calcium oxide modified fly ash. Environ. Eng. Res. 2021;26:190372.

13. Uzunova EL, Mikosch H. Adsorption of phosphates and phosphoric acid in zeolite clinoptilolite: Electronic structure study. Micropor. Mesopor. Mater. 2016;232:119-125.

14. Veneu DM, Schneider CL, de Mello Monte MB, Cunha OGC, Yokoyama L. Cadmium removal by bioclastic granules ( Lithothamnium calcareum ): batch and fixed-bed column systems sorption studies. Environ. Technol. 2018;39:1670-1681.

15. Wang Y-J, Wu C-D, Duan Y, Zhang Z-L. Removal of pollutants by enhanced coagulation combined PAC with variable charge soils: flocs' properties and effect of pH. Environ. Technol. 2016;37:2273-2280.

16. Wibowo E, Rokhmat M, Sutisna S, Khairurrijal, Abdullah M. Reduction of seawater salinity by natural zeolite (Clinoptilolite): Adsorption isotherms, thermodynamics and kinetics. Desalination 2017;409:146-156.

17. Asgari G, Roshani B, Ghanizadeh G. The investigation of kinetic and isotherm of fluoride adsorption onto functionalize pumice stone. J. Hazard. Mater. 2012; 217-218:123-132.

18. Azargohar R, Dalai AK. Production of activated carbon from Luscar char: Experimental and modeling studies. Micropor. Mesopor. Mater. 2005;85:219-225.

19. Hajati S, Ghaedi M, Mazaheri H. Removal of methylene blue from aqueous solution by walnut carbon: optimization using response surface methodology. Desalin. Water Treat. 2016;57: 3179-3193.

20. Kurt Louis S, Go-Un N, Yongseok H. Effectiveness of gold nanoparticle-coated silica in the removal of inorganic mercury in aqueous systems: Equilibrium and kinetic studies. Environ. Eng. Res. 2016;21:99:99-107.

21. Foroutan R, Esmaeili H, Abbasi M, Rezakazemi M, Mesbah M. Adsorption behavior of $\mathrm{Cu}(\mathrm{II})$ and $\mathrm{Co}(\mathrm{II})$ using chemically modified marine algae. Environ. Technol. 2018;39:2792-2800.

22. Aljerf L. High-efficiency extraction of bromocresol purple dye and heavy metals as chromium from industrial effluent by adsorption onto a modified surface of zeolite: Kinetics and equilibrium study. J. Environ. Manage. 2018;225:120-132.

23. Asgari G, Roshani B, Ghanizadeh G. The investigation of kinetic and isotherm of fluoride adsorption onto functionalize pumice stone. J. Hazard. Mater. 2012;217-218:123-132.

24. Abbasi M, Sabet A. Europhtal (8020) efficiently catalyzes the aerobic oxidation of in situ generated thiols to symmetric disulfides (disulfanes). J. Organomet. Chem. 2017;833:10-17.

25. Lakshmipathy R, Anvesh Reddy N, Sarada NC. Optimization of brilliant green biosorption by native and acid-activated watermelon rind as low-cost adsorbent. Desalin. Water Treat. 2015;54:235-244.

26. Hua M, Min H, Hongxia M, Huqing Y, Jian S. Preparation and characterization of $\mathrm{NiO} / \mathrm{MgO} / \mathrm{Al} 2 \mathrm{O} 3$ supported $\mathrm{CoPcS}$ catalyst and its application to mercaptan oxidation. Fuel Process. Technol. 2007;88:343-348.

27. Sadegh H, Mazloumbilandi M, Chahardouri M. Low-Cost Materials with Adsorption Performance. In: Martínez L, Kharissova O, Kharisov B, eds. Handbook of Ecomaterials. Springer, Cham; 2017.
28. Yang H, Wang Y, Bender J, Xu S. Removal of Arsenate and Chromate by Lanthanum-modified Granular Ceramic Material: The Critical Role of Coating Temperature. Sci. Rep. 2019;9.

29. Luo K, Pang Y, Li X, et al. Landfill leachate treatment by coagulation/flocculation combined with microelectrolysis-Fenton processes. Environ. Technol. 2018:1-9.

30. Dada O, Olalekan AO, Olantunya AP, Dada AM. Langmuir, Freundlich, Temkin and Dubinin - Radushkevich Isotherms Studies of Equilibrium Sorption of $\mathrm{Zn}^{2+}$ Unto Phosphoric Acid Modified Rice Husk. IOSR J. Appl. Chem. 2012;3:38-45.

31. Li X, Qiao K, He L, et al. Combined modification of ultra-stable Y zeolites via citric acid and phosphoric acid. Appl. Petrochemical Res. 2014;4:343-349.

32. Khan TA, Chaudhry SA, Ali I. Equilibrium uptake, isotherm and kinetic studies of $\mathrm{Cd}(\mathrm{II})$ adsorption onto iron oxide activated red mud from aqueous solution. J. Mol. Liq. 2015;202:165-175.

33. Zhu W, Liu J, Li M. Fundamental Studies of Novel Zwitterionic Hybrid Membranes: Kinetic Model and Mechanism Insights into Strontium Removal. Sci. World J. 2014;2014:485820.

34. Wan Ngah WS, Ariff NFM, Hashim A, Hanafiah MAKM. Malachite Green Adsorption onto Chitosan Coated Bentonite Beads: Isotherms, Kinetics and Mechanism. Clean. Soil Air Water. 2010;38:394-400.

35. Linhares B, Weber CT, Foletto EL, Paz DS, Mazutti MA, Collazzo GC. Activated carbon prepared from yerba mate used as a novel adsorbent for removal of tannery dye from aqueous solution. Environ. Technol. 2013;34:2401-2406.

36. Sugashini S, Begum KMMS. Optimization using central composite design (CCD) for the biosorption of $\mathrm{Cr}(\mathrm{VI})$ ions by cross linked chitosan carbonized rice husk (CCACR). Clean Technol. Environ. Policy. 2013;15:293-302.

37. Derringer G, Suich R. Simultaneous Optimization of Several Response Variables. J. Qual. Technol. 1980;12:214-219.

38. Azargohar R, Dalai AK. Production of activated carbon from Luscar char: Experimental and modeling studies. Micropor. Mesopor. Mater. 2005;85:219-225.

39. Hajati S, Ghaedi M, Mazaheri H. Removal of methylene blue from aqueous solution by walnut carbon: optimization using response surface methodology. Desalin. Water. Treat. 2016;57/7: 3179-3193.

40. Roosta M, Ghaedi M, Daneshfar A, Darafarin S, Sahraei R, Purkait MK. Simultaneous ultrasound-assisted removal of sunset yellow and erythrosine by ZnS:Ni nanoparticles loaded on activated carbon: optimization by central composite design. Ultrason. Sonochem. 2014;21:1441-1450.

41. Suzuk M. Adsorption Engineering. Tokyo: Kodansha; 1990. p. 128-132.

42. Dehghan P, Abbasi M, Mofarahi M, Azari A. Adsorption of synthetic and real Kinetic Hydrate Inhibitors (KHI) wastewaters on activated carbon: adsorption kinetics, isotherms, and optimized conditions. Sep. Sci. Technol. 2020;1-12.

43. Margeta K, Logar NZ, Siljeg M, Farkas A. Natural Zeolites in Water Treatment - How Effective is Their Use, Water Treatment, Walid Elshorbagy and Rezaul Kabir Chowdhury, IntechOpen; 2013.

44. Hamdaoui O, Naffrechoux E. Modeling of adsorption isotherms of phenol and chlorophenols onto granular activated carbon 
Part I. Two-parameter models and equations allowing determination of thermodynamic parameters. J. Hazard. Mater. 2007; 147:381-394.

45. Hu X-j, Wang J-s, Liu Y-g, et al. Adsorption of chromium (VI) by ethylenediamine-modified cross-linked magnetic chitosan resin: Isotherms, kinetics and thermodynamics. J. Hazard. Mater. 2011;185:306-314. 